\title{
Bazı Pamuk Melezlerinin Verim ve Lif Kalite Özelliklerinin İncelenmesi
}

\author{
*Mehmet ÇOBAN ${ }^{1} \quad$ Süleyman ÇiçEK ${ }^{1} \quad$ Fatih KÜÇÜKTABAN ${ }^{1}$ \\ Levent YAZICl ${ }^{2} \quad$ Hakan ÇiFTÇiं ${ }^{3}$ \\ ${ }^{1}$ Pamuk Araştırma Enstitüsü Müdürlüğü, Aydın \\ ${ }^{2}$ Orta Karadeniz Geçit Kuşağı Tarımsal Araştırma Enstitüsü Müdürlüğü, Tokat \\ ${ }^{3}$ Koyunculuk Araştırma Enstitüsü Müdürlüğü, Balıkesir \\ *Sorumlu yazar e-posta (Corresponding author e-mail): coban.mehmet44@gmail.com
}

Öz

Bu çalışma, Gossypium hirsutum L. türüne ait Şahin 2000, BA 308 ve Lider çeşitleri, [(G. hirsutum x G. barbadense $\left.F_{1}\right) \times(G$. arboreum $\times$ G. thurberi $\times$ G. hirsutum)] türleri arasında yapılan melezleme sonucu geliştirilen lif kalite özellikleri ile üstün Delcerrro çeşidi melezlenerek oluşturulan $F_{1}$ popülasyonunda bazı lif kalite özellikleri yönünden Nazilli koşullarına uygun melez kombinasyonları tespit etmek amacıyla yapılmıştır. F 1 melez kuşağı ebeveynleri ile birlikte, 2012 yılında tesadüf blokları deneme deseninde 4 tekerrürlü olarak ekilmiştir. Yürütülen araştırma sonucunda, anaçların kütlü verimi 86.50 ile $78.40 \mathrm{~g} / \mathrm{bitki}$, randımanı \%40.20 ile \%30.7, lif uzunluğu 34.57 ile 28.88 mm, lif inceliği 4.32 ile 4.70 micronaire, lif mukavemeti 44.83 ile 29.08 g/tex, kısa lif oranı \%8.93 ile \%6.85; melezlerin kütlü verimi ise 88.75 ile $6770 \mathrm{~g} / \mathrm{bitki}$, randımanı $\% 38.08$ ile \%34.38, lif uzunluğu 33.85 ile 32.30 mm, lif inceliği 4.93 ile 4.12 micronaire, lif mukavemeti 41.10 ile 35.68 g/tex, kısa lif oranı \%8.20 ile \%6.85 arasında değişim göstermiştir. Kütlü verimi, randıman ve lif mukavemeti yönünden birer kombinasyonda olumlu ve önemli düzeyde heterosis tespit edilmiştir. Melezlerden kütlü verimi yönünden bir, lif mukavemeti yönünden iki ve kısa lif oranı yönünden bir kombinasyonda olumsuz ve önemli düzeyde heterosis tespit edilmiştir.

Anahtar Kelimeler: Pamuk, melezleme, heterosis, ekonomik heterosis

\section{Investigation of Yield and Fiber Quality Properties of Some Cotton Hybrid}

\begin{abstract}
This study was caried out to determine the superior $F_{1}$ combination with desirable fiber quality properties for Nazilli conditions. For this aim Şahin 2000, BA 308 and Lider (Gossypium hirsutum L.) cotton varieties was crossed by Delcerro [(G. hirsutum x G. barbadense $\left.F_{1}\right) \times(G$. arboreum x G.thurberi $x$ G. hirsutum)] superior variety with fiber characteristics. $F_{1}$ generation and their parents were planted according to randomized complete block design with four replications in 2012. As a result of conducted research seed cotton yields for parents ranged between 86.50 to 78.40 g plant $^{-1}$, ginning outturn 40.20 to $30.7 \%$, fiber length 34.57 to $28.88 \mathrm{~mm}$, fiber fineness 4.32 to 4.70 micronaire, fiber strength 44.83 to $29.08 \mathrm{~g}^{-1}$, short fiber index 8.93 to $6.85 \%$; seed cotton yields for crosses ranged between 88.75 to 67.70 g plant $^{-1}$, ginning outturn 38.08 to $34.38 \%$, fiber length 33.85 to $32.30 \mathrm{~mm}$, fiber fineness 4.93 to 4.12 micronaire, fiber strength 41.10 to $35.68 \mathrm{~g} / \mathrm{tex}$, short fiber index 8.20 to $6.85 \%$. Positive significant heterosis were determined in one combinations for seed cotton yields, ginning outturn and fiber strength. Negative significant heterosis were determined in one combinations for seed cotton yields and short fiber index, in two combination for fiber strength.
\end{abstract}

Keywords: Cotton, hybridization, heterosis, useful heterosis 


\section{Giriş}

$\mathrm{P}$ amuk, yüzyıllardır birçok ülkede başta tekstil olmak üzere farklı sanayi kollarının en önemli hammaddesidir. Sentetik lif üretiminin sürekli artmasına karşın dünya tekstil sanayinde kullanılan hammaddeler arasındaki yeri ve önemini korumaktadır. Kullanılan dokuma hammaddesinin \% 60' $\%$ pamuktan karşılanmaktadır. Tarımı ve sanayisi ile geniş bir iş alanı sağlarken, lifi ile tekstil sanayisine, çiğiti ile yağ sanayisine, küspesi ile hayvancılık sektörüne, ihracatı ile dış ticaretimize çok önemli katkıları olan endüstriyel bir üründür (Anonim 2010).

Dünya nüfusu ve yaşam standardının artması, gıda maddeleriyle birlikte pamuğun da önemini her geçen gün artırmaktadır. Türkiye 697.000 ton pamuk üretimi ile dünyada 7 . sırada, pamuk tüketiminde 1.372 .000 ton ile Çin, Hindistan ve Pakistan'ın ardından 4. sırada ve dünyada lif pamuk ithal eden ülkeler arasında 795.000 ton ile 4. sırada bulunmaktadır (Anonim 2015). Türkiye tekstilde gerek üretim miktarı, gerekse ürün kalitesi ile önde gelen ülkelerden birisidir. Tekstil sektörümüzün iş gücü ve enerji kullanımı çok ucuz olan Çin, Pakistan, Hindistan gibi ülkeler ile rekabet edebilmesinin tek yolu kalitesi yüksek ürün üretebilmekten geçmektedir.

Pamuk lifi, diğer bitkisel ve sentetik liflere göre daha fazla tercih edilmekte, dünya tekstil ürünleri üretiminde giderek daha büyük önem kazanmaktadır. Ancak Türkiye'de toplam pamuk lifi üretimi tekstil sanayisinin hammadde intiyacının gerisinde kalmakta ve her yıl toplam lif üretimi kadar pamuk lifi ithal edilmektedir. Bu da ülkemiz ekonomisi için ciddi kayıplara sebep olmakta ve tekstil sektörümüzü giderek hammadde temini bakımından dışarıya bağımlı kılmaktadır. Ülkemizin planlı bir şekilde pamuk üretimini verim ve lif kalitesi bakımından arttırması gerekmektedir.

Upland pamukları (Gossypium hirsutum L.), verim potansiyelleri yüksek, vejetasyon süresi orta-uzun, çırçır randımanları >\%39 değerinde ve dünyada yetiştirilen pamukların \%80'inden fazlasını oluştururlar. Dolayısıyla da ülkemiz pamuklarının \%99.5'i Gossypium hirsutum L. türü pamuklardır (Gürel ve ark. 2000). Ülkemizde pamuk ıslah çalışmaları, 1950-60'। yıllarda başlamış ve bazı çeşitler geliştirilmiş olmasına rağmen ülkemizde ıslah edilmiş çeşit sayısı günümüz çiftçi ve tekstil sanayicilerinin intiyaç ve taleplerini karşılamaktan oldukça uzak görünmektedir.

Birim alandan elde edilen ürün miktarının ve kalitenin artırıması, pamuk ıslah programlarının öncelikli hedefini oluşturmaktadır (Gençer ve Yelin 1983). Ancak, ıslah programındaki başarı, amacın iyi belirlenebilmesinin yanında, yapılacak ıslah çalışmasında kullanılacak yöntemin ve bu yöntemler içinde kullanılacak anaçların iyi seçilmesi; anaçlara ilişkin melez kombinasyonlardaki genetik yapılarının iyi bir şekilde kombine edilmesi ile mümkündür. Bu nedenle ıslahçının başarıya ulaşabilmesi için amacını iyi belirleyerek ebeveyn seçiminde dikkatli olmasının yanında, geniş bir varyabilite oluşturarak izlenebilecek Islah yöntemlerini erken kuşaklarda belirlemesi önem arz etmektedir (Gençer 1978).

Yüksek verimli ve lif teknolojik özellikleri üstün yeni pamuk çeşitlerinin elde edilmesi için pamuk ıslahı çalışmalarının kesintisiz ve yoğun bir şekilde sürdürülmesi gerekmektedir. Son yıllardaki çalışmalar ile birlikte, pamuk veriminin arttırıması ve endüstriyel amaçlara uygun lif teknolojik özelliklerinin geliştirilmesi için klasik ıslah çalışmaları da devam etmektedir.

Gossypium hirsutum L. türüne ait pamuk çeşitlerinin verim ve diğer agronomik özelliklerini koruyarak lif kalite özelliklerini geliştirmek amacıyla yapılan türler arası (Gossypium hirsutum L. x Gossypium barbadense L.) melezleme çalışmalarının oldukça eskiye dayandığı ve ilk melezleme çalışmalarının 1860'ı yıllarında yapıldığı bildirilmektedir (Smith et al. 1999).

Gossypium hirsutum L. türüne ait çeşitlerin verim kapasiteleri korunarak, lif kalite özelliklerinin geliştirilmesi amacıyla türler arası melezleme çalışmaları sonucunda Gossypium barbadense L. türüne ait çeşitlerden Gossypium hirsutum $L$. türüne ait çeşitlere gen aktarabilme şansının bulunduğu ifade edilmiştir (Akdemir ve ark. 2001). Aynı şekilde türler arası melezleme ile lif kalite özelliklerin geliştirilebileceği bildirilmiştir (Culp ve Harrell, 1974; Culp, 1979).

Ülkemiz pamuk tohumculuğu bakımından büyük oranda dışarıya bağımlıdır ve yüksek fiyatlar ödeyerek pamuk tohumluğu temin etmektedir. Pamuk tohumculuğu sektöründe 
karşılaşılan diğer önemli bir problem ise yaygın olarak tarımı yapılan çeşit sayısının az olmasıdır. Bu çeşitlerin bir çoğu istenilen düzeyde üstün lif kalitesi ile ilgili bütün özellikleri taşımamaktadır. Çiftçilerimize ve sanayicimize alternatif ürünler sunulması gerekmektedir. Bu çalışmanın esas amaçı lif kalite özelliklerinin kalıtımının erken generasyonlarda tahmin edilmesidir.

$\mathrm{Bu}$ çalışma oluşturulan melez popülasyonların $F_{1}$ generasyonunda verim ve lif kalite özelliklerinin karşılaştırılması ve aynı zamanda incelenen özelikler bakımından üstün melez popülasyonlarının belirlenmesi amacıyla yapılmıştır.

\section{Materyal ve Yöntem}

Çalışmada, Gossypium hirsutum L. türüne ait Şahin 2000, BA 308 ve Lider çeşitleri ana, [(G. hirsutum x G. barbadense $\left.F_{1}\right) \times(G$. arboreum x G.thurberi x G. hirsutum)] türleri arasında yapılan melezleme sonucu geliştirilen lif kalite özellikleri ile üstün Delcerro çeşiti baba ebeveyn olarak kullanılmıştır. Çalışmada baba ve ana olarak kullanılacak çeşitlerin çiçeklenme tarihlerinin birbirlerine denk getirilebilmesi için, ana ebeveynler 19.05.2011 ve 30.05.2011 olmak üzere iki zamanlı olarak ekilmiştir. Birinci ekimde baba olarak kullanılacak çeşitler ile ana ebeveynler, ikinci ekimde sadece ana ebeveynler sıra arası $0.7 \mathrm{~m}$, sıra üzeri $0.2 \mathrm{~cm}$ ve dörder sıralı olarak ekilmiştir. Ebeveynler çoklu dizi uyarınca melezlenmiştir. Melezlemelerde Pohelman (1959)'ın belirttiği teknikler uygulanarak melezlemeler sırasında kayıt tutulmuş, silkme gösteren etiketler toplanarak yeterli miktarda tohum elde edinceye kadar kombinasyonlar üzerinde çalışılmıştır. Melezlenen çiçek sayısı ve her bir kozadan elde edilecek tohum sayısı dikkate alınarak her kombinasyondan 200 tohum elde edilebilecek şekilde melezlemelere devam edilmiştir. Melezlenen çiçeklerin tutum oranını arttırmak amacıyla 1. pozisyondaki çiçekler üzerinde çalışılarak, melezlenemeyen çiçekler ise koparılmıştır.

Hasat döneminde açan kozalar sapları ile birlikte, aynı kombinasyonda olan kozalar bir torbada olacak şekilde toplanmıştır. Tohumlar liflerinden elle ayrılarak $F_{1}$ tohumlukları elde edilmiştir.
$F_{1}$ melez kuşağı ebeveynleri ile birlikte, 17 Mayıs 2012 'de tesadüf blokları deneme deseninde 4 tekerrürlü olarak ekilmiştir.

Genotiplere ait parseller; $7 \mathrm{~m}$ uzunluğunda ve 1 sıra; sıra arası $0.7 \mathrm{~m}$, sıra üzeri ise $0.2 \mathrm{~m}$ olacak şekilde düzenlenmiştir. Ekimle birlikte taban gübresi olarak 5 kg/da kompoze gübre (20 -20 -0) uygulanmıştır. Pamukta birinci sulama yapılmadan hemen öncesinde $9 \mathrm{~kg} / \mathrm{da}$ azot içeren Amonyum Nitrat gübresi üst gübre olarak parsellere uygulanmıştır. Denemede üç sulama, iki çapalama ve bir ot kırımı yapılmıştır. Hasat, 15 Ekim 2012 tarihinde el ile parsel başı ve sonundan 1 metrelik bölümlerin kenar tesiri olarak elemine edilmesinden sonra; popülasyonun genel yapısını temsil eden, ardışık 10 tek bitki üzerinden yapılmıştır.

İncelenen her bir özellik yönünden $F_{1}$ döl kuşağındaki heterosis değerleri Hallauer and Miranda (1971) göre hesaplanmıştır. Heterosis değerleri yanında, Davis (1978) tarafından tanımlanan kontrol çeşide üstünlük değerleri de saptanmıştır. Bölgede yaygın olarak ekimi yapılan BA 308 çeşidi kontrol çeşit olarak kullanılmıştır. Heterosisteki farkın ( $\left.F_{1}-M P\right)$ önemliliğini kontrol için $t$ testi kullanılmıştır. Cohran and Cox (1957) tarafından önerilen yöntemle t değerinin bulunmasında gerekli olan standart hata (Sh) saptanmıştır.

Önemlilik testi için $t:\left[F_{1}-\left(P_{1}+P_{2}\right) / 2\right] / S h$ değeri kullanılmıştır.

\section{Bulgular ve Tartışma}

İncelenen özeliklerin varyans analiz sonuçları, Çizelge 1'de verilmiştir. Çizelge 1'den incelenen özelliklerin tamamı için aralarındaki farklılıkların istatistiki olarak önemli olduğu görülmektedir. Yürütülen araştırma sonucunda, anaçların verimi 86.50 ile $78.40 \mathrm{~g} / \mathrm{bitki}$ arasında değişim gösterirken, Şahin 2000*Delcerro melez kombinasyonundan $88.75 \mathrm{~g} / \mathrm{bitki}$ verim elde edilmiştir. Anaç ve melezlerden elde edilen verim ortalamaları üç verim grubuna ayrılmıştır. Ebeveynlerin çırçır randımanı \%40.20 ile \%30.7 arasında yer almasına rağmen melez kombinasyonların çırçır randımanı değerleri \%34.38 ile \%38.08 arasında değişim göstermiştir. Anaçların lif uzunluğu 34.57 ile $28.88 \mathrm{~mm}$ iken melezlerin 33.85 ile 32.30 arasında yer almıştır. Lif inceliği bakımında anaçlar 4.32 ile 4.70 micronaire arasında 
değişim gösterirken, melezlerin lif inceliği 4.12 - 4.93 micronaire arasında değişmiştir. Lif mukavemeti açısından anaçların ortalamaları 44.83 - $29.08 \mathrm{~g} /$ tex arasında değişim gösterirken melezlerin ortalamaları 41.10 $35.68 \mathrm{~g} /$ tex arasında kalmıştır. Kısa lif içeriği bakımında anaçlar \%8.93 ile \%6.85 arasında değişim göstermiş olup melezlerde \%8.20 ile \%6.85 ortalama değerleri arasında değişim göstermiştir.

Verim bakımından melezlerin heterosis değerleri \%11.71 ile \%-17.79 arasında değişmektedir. Şahin 2000*Delcerro melez kombinasyonunda heterosis değeri pozitif ve önemli bulunurken Lider*Delcerro kombinasyonunda negatif ve önemli bulunmuştur. Güvercin (2011)'in türler arası yapmış olduğu melezleme çalışmasında çırçır randımanı için tüm kombinasyonlarda olumsuz yönde heterosis hesaplarken, yapmış olduğumuz çalışmada randıman değerleri bakımından \%7.42 ile Lider*Delcerro melez kombinasyonunda önemli ve olumlu heterosis tespit edilmiştir.

Lif inceliği bakımından BA 308*Delcerro (\%1.11) ve Şahin $2000 *$ Delcerro (\%-3.45) melez kombinasyonlarında önemli ve olumlu heterosis hesaplanırken Lider*Delcerro (\%5.34) olumsuz ve önemli düzeyde heterosis hesaplanmıştır. Lif uzunluğu bakımından tüm kombinasyonlarda olumlu yönde heterosis değerleri tespit edilmiştir.

Ekonomik heterosis bakımından melezleri incelediğimizde, verim bakımından Şahin 2000*Delcerro kombinasyonunda olumlu yönde heterosis hesaplanırken diğer iki melez kombinasyonunda olumsuz yönde heterosis değerleri hesaplanmıştır. Randıman özelliği için tüm kombinasyonlarda olumsuz ve önemli düzeyde ekonomik heterosis değerleri hesaplanmıştır. Lif uzunluğu ve lif mukavemeti özellikleri bakımından tüm melez

Çizelge 1. İncelenen Özellikler bakımından varyans analizi sonuçları

Table 1. Variance analysis results of parameters

\begin{tabular}{lccccccc}
\hline & SD & \multicolumn{1}{c}{$\begin{array}{c}\text { Verim } \\
\text { g bitki }\end{array}$} & $\begin{array}{c}\text { Randıman } \\
(\%)\end{array}$ & $\begin{array}{c}\text { Lif } \\
\text { Uzunluğu } \\
(\mathrm{mm})\end{array}$ & $\begin{array}{c}\text { Lif İnceliği } \\
(\mathrm{mic})\end{array}$ & $\begin{array}{c}\text { Lif } \\
\text { Mukavemeti } \\
(\mathrm{g} / \text { teks })\end{array}$ & $\begin{array}{c}\text { Kısa Lif } \\
\text { Içeriği }(\%)\end{array}$ \\
\hline Çeşit & 6 & $195.333 *$ & $40.405 *$ & $17.258 *$ & $0.282 *$ & $108.668 *$ & $2.244 *$ \\
Tekerrür & 3 & 35.560 & 0.278 & 0.028 & 0.052 & 5.571 & 0.470 \\
Hata & 21 & 39.804 & 0.406 & 0.164 & 0.028 & 2.668 & 0.264 \\
\hline
\end{tabular}

* $=\% 5$ düzeyinde önemli

* $=$ significant at \%5 level

Çizelge 2. İncelenen özellikler yönünden anaçların ve melezlerin ortalama değerleri

Table 2. Averages of parents and hybrids of investigated parameters

\begin{tabular}{|c|c|c|c|c|c|c|c|c|c|c|c|c|}
\hline \multirow{2}{*}{$\begin{array}{l}\text { Genotip } \\
\text { Şahin } \\
2000^{*} \text { Delcerro }\end{array}$} & \multicolumn{2}{|c|}{$\begin{array}{l}\text { Verim } \\
\text { g/bitki }\end{array}$} & \multicolumn{2}{|c|}{$\begin{array}{l}\text { Randıman } \\
(\%)\end{array}$} & \multicolumn{2}{|c|}{$\begin{array}{l}\text { Lif } \\
\text { Uzunluğu } \\
\text { (mm) }\end{array}$} & \multicolumn{2}{|c|}{$\begin{array}{l}\text { Lif İnceliği } \\
\quad \text { (mic) }\end{array}$} & \multicolumn{2}{|c|}{$\begin{array}{l}\text { Lif Mukavemeti } \\
\quad(\mathrm{g} / \mathrm{teks})\end{array}$} & \multicolumn{2}{|c|}{$\begin{array}{c}\text { Kısa Lif } \\
\text { İçeriği (\%) }\end{array}$} \\
\hline & 88.75 & A & 35.30 & C & 33.37 & B & 4.12 & A & 35.68 & $\mathrm{C}$ & 8.20 & $\begin{array}{l}B \\
C\end{array}$ \\
\hline Lider & 86.50 & $A B$ & 40.20 & $A$ & 28.88 & $\mathrm{~F}$ & 4.70 & $\mathrm{BC}$ & 34.30 & $\mathrm{C}$ & 7.90 & B \\
\hline BA 308 & 85.00 & $A B$ & 38.40 & $B$ & 31.54 & $\mathrm{D}$ & 4.63 & $B$ & 33.90 & C & 8.10 & $\mathrm{~B}$ \\
\hline Şahin 2000 & 80.50 & $A B$ & 37.65 & $B$ & 30.00 & $E$ & 4.32 & $A$ & 29.08 & $\mathrm{D}$ & 8.93 & $\mathrm{C}$ \\
\hline BA 308*Delcerro & 79.30 & B & 34.38 & C & 33.85 & B & 4.65 & B & 38.93 & B & 6.85 & $A$ \\
\hline Delcerro & 78.40 & B & 30.70 & $D$ & 34.57 & $A$ & 4.66 & B & 44.83 & $A$ & 6.85 & $A$ \\
\hline LiderDelcerro & 67.70 & $\mathrm{C}$ & 38.08 & B & 32.30 & $\mathrm{C}$ & 4.93 & $\mathrm{C}$ & 41.10 & B & 7.60 & $\begin{array}{l}A \\
B\end{array}$ \\
\hline C.V. & 7.80 & & 1.71 & & 1.26 & & 3.63 & & 4.44 & & 6.61 & \\
\hline LSD & 9.37 & & 0.95 & & 0.60 & & 0.25 & & 2.43 & & 0.76 & \\
\hline
\end{tabular}


Çizelge 3. İncelenen özellikler yönünden $\mathrm{F}_{1}$ melez popülasyonunun heterosis ve ekonomik heterosis değerleri (\%)

Table 3. Heterosis and useful heteorsis (\%) of $F_{1}$ hybrid population for investigated traits

\begin{tabular}{|c|c|c|c|c|c|c|c|}
\hline & & BA $308^{*}$ Delcerro & & Lider*Delcerro & & Şahin $2000 *$ Delcerro & \\
\hline \multirow{6}{*}{$\begin{array}{l}\frac{0}{\omega} \\
\frac{0}{0} \\
\frac{0}{1} \\
\frac{0}{1}\end{array}$} & Verim & -2.94 & & -17.79 & * & 11.71 & * \\
\hline & Randıman & -0.49 & & 7.42 & * & 3.29 & \\
\hline & Lif Uzunluğu & 2.41 & & 1.81 & & 3.36 & \\
\hline & Lif İnceliği & 0.11 & & 5.34 & & -8.24 & \\
\hline & Lif Mukavemeti & $-1.11 *$ & * & 3.88 & * & -3.45 & * \\
\hline & Kısa Lif İçeriği & 8.36 * & * & -3.05 & & -3.93 & \\
\hline \multirow{6}{*}{ 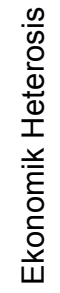 } & Verim & -6.71 & & -20.35 & & 4.41 & \\
\hline & Randıman & -10.47 * & * & -0.83 & * & -8.07 & * \\
\hline & Lif Uzunluğu & 7.32 * & * & 2.41 & * & 5.80 & * \\
\hline & Lif İnceliği & $0.43 *$ & * & 6.48 & * & -11.02 & * \\
\hline & Lif Mukavemeti & 14.84 * & * & 21.24 & * & 5.25 & * \\
\hline & Kısa Lif İçeriği & 15.43 * & * & 6.17 & * & -1.23 & * \\
\hline
\end{tabular}

kombinasyonlarda olumlu ve önemli düzeyde ekonomik heterosis tespit edilmiştir. Lif inceliği bakımından Şahin 2000*Delcerro melez kombinasyonunda olumlu ve önemli ekonomik heterosis tespit edilirken diğer iki melez kombinasyonda olumsuz ve önemli ekonomik heterosis değerleri tespit edilmiştir. Lif mukavemeti ve lif inceliği için hesapladığımız ekonomik heterosis değerleri Güvercin ve Sunulu (2010) sonuçları ile uyum içerisindedir. Kısa lif içeriği açısından melez kombinasyonlardaki ekonomik heterosisi değerlendirdiğimizde Şahin 2000*Delcerro melez kombinasyonunda olumsuz ve önemli ekonomik heterosis tespit edilirken diğer iki melez kombinasyonda olumlu ve önemli ekonomik heterosis değerleri tespit edilmiştir. Verim bakımından Şahin2000* Delcerro melez kombinasyonunda olumlu yönde ekonomik heterosis hesaplanmıştır.

\section{Sonuç}

Melez kombinasyonlarda hesapladığımız heterosis ve ekonomik heterosis değerleri için verim ve lif kalite özelliklerini birlikte değerlendirdiğimizde; Şahin 2000*Delcerro melez kombinasyonundan kabul edilebilir verim ve randıman değerlerine sahip lif kalite özellikleri bakımından üstün genotiplerin elde edilebileceği sonucuna varılmıştır. Söz konusu melez kombinasyon ile tüm genotipleri birlikte değerlendirdiğimizde en yüksek verim ve en ince lif değerleri elde edilmiştir.

\section{Kaynaklar}

Anonim 2010. Pamuk Raporu. Sanayi ve Ticaret Bakanlığı Teşkilatlandırma Genel Müdürlüğü, Ankara

Anonim 2015. Cotton World Markets and Trade, United States Department of Agriculture, Foreign Agricultural Services, June 2015

Akdemir H., Gürel A., Karadayı H.B., 2001. Ege bölgesi koşullarına uygun uzun-ince elyaflı pamukların adaptasyonu üzerine araştırmalar. Anadolu, Ege Tar. Arş. Ens. Derg., 11 (2): 56-75

Cohran W.G., Cox G.M., 1957. Experimental Designs. John Willey Sons Inc, New York.

Culp T.W., Harrell D.C., 1974. Breeding Quality Cotton at the PEE DEE Experiment Station Florence, S.C. USDA ARS-S-30, New Orleans, LA

Culp T.W., 1979. Notice to plant breeders and geneticists relative to release of five Noncommercial breeding stocks of extra-long staple upland cotton, Sealand 542, Earlistaple 7, Line F (Hybrid 330), FJA, and FTA. S.C. Agric. Exp. Stn Bull

Davis D.D., 1978. Hybrid cotton, specific problems and potentials. Adv. Agronomy 30 : 129-147

Gençer O., 1978. Gossypium hirsutum L, ve Gossypium barbadense L. Türlerinden Sekiz Pamuk Çeşidinin Diallel Melezlerinde Verim ve Kalite ile İlgili Başlıca Özelliklerin Kalıtımı Üzerinde Araştırmalar. Çukurova Üniversitesi, Ziraat Fakültesi, Doçentlik Tezi, Adana 
Gençer O., Yelin D., 1983. Pamuk bitkisinde (Gossypium hirsutum L.) erkencilik kriterlerinin kalıtımı ve verimle ilişkileri üzerine bir araştırma. Bölge Pamuk Araştırma Enstitüsü Müdürlüğü. Adana. Yayın No: 40

Güvercin R.Ş., Sunulu S., 2010. Bazı pamuk (Gossypium hirsutum L.x Gossypium barbadense L.) melezlerinin lif özelliklerinde heterosis ve korelasyon katsayıları. YYÜ Tar. Bil. Derg. (YYU J AGR SCI), 20 (2): 68-74

Güvercin R.Ş., 2011. Pamukta (Gossypium ssp.) $F_{1}$ melezlerinin lif verimine etkili bazı karakterlerde heterosis, heterobeltiosis ve ekonomik heterosis. Tarım Bilimleri Dergisi Journal of Agricultural Sciences, 17: 113ロ121
Gürel A., Akdemir H., Emiroğlu Ş.H., Kadoğlu H. Karadayı H.B., 2000. Türkiye lif bitkileri. Türkiye Ziraat Mühendisliği V. Teknik Kongresi, 17-21 Ocak, Ankara, 525-566

Hallauer A.R., Miranda J.B., 1971. Quantitave Genetics in Maize Breeding. lowa State Uni. Press Ames., USA

Smith C.W., Cantrell G.R., Moser H.S., Oakley S.R., 1999. History of Cultivar Development in the United States. In Cotton: Origin, History, Technology, and Production, (Editörler: Smith CW, Cothren JT) John Wiley \& Sons, pp. 99171, New York

Pohelman M.J., 1959. Breeding Field Crops. Holt. Rinehart and Winston Inc., New York 